\title{
The Role of Neurologist in the Assessment and Treatment of Depression
} Depresyonun Tanısı ve Sağaltımında Nöroloğun Yeri

\author{
Emre Kumral ${ }^{1}$, (1 Fatma Ece Bayam² \\ ${ }^{1}$ Ege University Faculty of Medicine, Department of Neurology, Izmir, Turkey \\ 2Uskudar University Faculty of Medicine, Department of Psychology, Istanbul, Turkey
}

\begin{abstract}
In neurologic illness, depression contributes significantly to impairments in quality of life, independent of the severity of the disease. In the evolution of neurodegenerative disorders, depression may predate neurologic signs and symptoms, and there is some evidence that depressive illness itself may be a risk factor in some dementias. Data on the treatment of depression in neurologic disease are scarce, and often the treatment advice is based on the personal views of psychiatrists. In some patients, diagnosis of depression in neurologic diseases can be particularly hard because of communication difficulties and disturbances of emotional expression as a result of neurologic disorders. However, effective screening and diagnostic tools have been developed for the recognition of depression in neurologic disorders. In recent years, there have been large quantities of clinical trials that supported the critical role of the neurologist in assessing and treating depressive symptoms to the point of remission. The intention of this review was to demonstrate the importance and role of a neurologist in the diagnosis and treatment of depression in neuropsychiatric diseases.
\end{abstract}

Keywords: Brain injury, depression, dementia, epilepsy, multiple sclerosis, Parkinson's disease

$\ddot{O} \mathbf{z}$

Nörolojik hastalıklarla beraber görülen depresyon, nörolojik hastalığın ciddiyetinden bağımsız olarak yaşam kalitesindeki bozulmalara önemli ölçüde katkıda bulunur. Nörodejeneratif hastalıkların seyrinde, depresyon nörolojik belirti ve semptomları ortaya çıkarabilir ve bazı bunamalarda depresif hastalığın kendisinin bir risk faktörü olabileceğine dair bazı kanıtlar vardır. Nörolojik hastalıklarda depresyon sağaltımı için kanıtlar sınırlıdır ve genellikle tedavi önerisi psikiyatristlerin kararına dayanmaktadır. Nörolojik durumlarda depresyonun teşhisi, iletişim güçlüğ̈̈̈ ve altta yatan nörolojik hastalığın bir sonucu olarak duygusal ifadedeki değişiklikler nedeniyle özellikle zor olabilir. Bununla birlikte, nörolojik bozukluklarda depresyonun tanınması için etkili tarama ve tanılama yöntemleri geliştirilmiştir. Son yıllarda, depresif rahatsızlıkların tanınması ve sağaltımı konusundaki nöroloğun kritik rolünü destekleyen çok sayıda klinik çalışma yapılmıştır. Bu derleme, nöropsikiyatrik hastalıklarda depresyonun tanısında ve sağaltımında bir nöroloğun önemini ve rolünü göstermeyi amaçlamaktadır.

Anahtar Kelimeler: Beyin hasarı, depresyon, demans, epilepsi, multipl skleroz, Parkinson hastalığ

\section{Introduction}

For 10 years, tremendous data have accumulated concerning the neuropsychiatric concept of neurologic diseases, which was largely available in $20^{\text {th }}$ century world medicine. It is now recognized that psychiatric features are the principal parts of the majority of neurologic disorders, which affect the outcome of diseases, and they have a major role in the symptoms of these illnesses. In the last year, because of the health policies of countries, there has been a tendency to separate close entities of clinical neurosciences. Psychological and cognitive views of neurologic disease could not be distinguished because both are part of each other, either by neural networks or by neurotransmitters $(1,2)$. In a neurologic disease, neurologic findings such as motor, sensorial, and cerebellar deficits could exist, mostly by an emotional and cognitive disorder. The main reason for the coexistence with neurologic and psychiatric findings are that the same physiologic pathways and anatomic structures are intertwined with the use of both systems (Figure 1) (3). The findings of neurologic diseases and psychiatric aspects can be classified and evaluated under the heading of emotion, thought, judgment, abstraction, and reasoning. The most common psychiatric disorders include psychotic symptoms, mood disorders, and other cognitive deficits. In this article, we discuss the psychiatric findings in neurologic

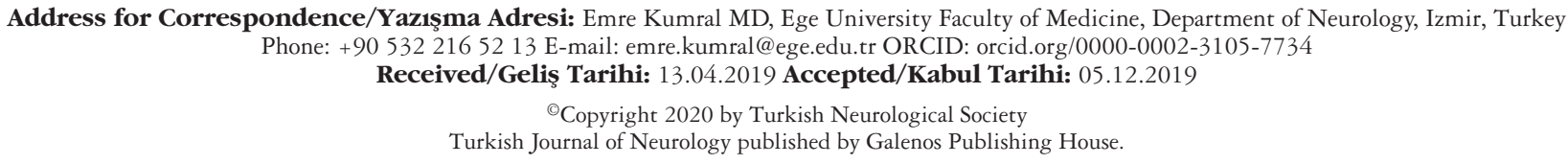


diseases and the importance of the neurologist in the assessment, diagnosis, and treatment of depression.

\section{Search Strategy and Data Extraction}

Data on depression following neurologic diseases were identified from the following computerized databases (last searched January 2019): PubMed, Cochrane reports, EMBASE, PsychINFO, applied science and technology plus, biological abstracts, general science plus, Arts and Humanities Index, Science Citation Index, Social Sciences Citation Index, and digital dissertations using terms and strategy based on the cochrane stroke group methodology. We also contacted researchers and pharmaceutical companies, attended relevant conferences, and hand-searched the four main neurology journals. Two reviewers (E.K. and F.E.B) extracted and reached agreement on data from included articles using a standard electronic data form. Information from multiple articles reporting on the same data source was combined.

\section{Assessment of Depression in Neurologic Disorders}

Depressive disorders comprise major depressive disorder, disruptive mood dysregulation disorder, persistent depressive disorder, premenstrual dysphoric disorder, substance/medicationinduced depressive disorder, depressive disorder due to another medical condition, other specified depressive disorder, and unspecified depressive disorder according to the Diagnostic and Statistical Manual of Mental Disorders, Fifth Edition (DSM-V) criteria (Table 1) (4). Besides the DSMs (eg, DSM-IV, DSM-V),

\section{Table 1. Major depressive disorder diagnostic criteria}

A. Five (or more) of the following symptoms were present in the same two-week period:

1. Depression almost every day.

2. All or almost all of the interests or pleasures have decreased significantly.

3. Significant weight loss.

4. Insomnia or hypersomnia.

5. Psychomotor agitation or retardation.

6. Fatigue or energy loss.

7. Feelings of worthlessness or excessive or inappropriate guilt.

8. Diminished ability to think or concentrate, or indecisiveness.

9. Suicide attempt or a specific plan for committing suicide.

B. Symptoms yield significant impairment in social, occupational or other important function areas.

C. Depression is not attributable to the effects of a substance or to another medical disease.

D. Major depressive episode is not better explained by psychotic disorders.

E. There was never a manic event or a hypomanic event

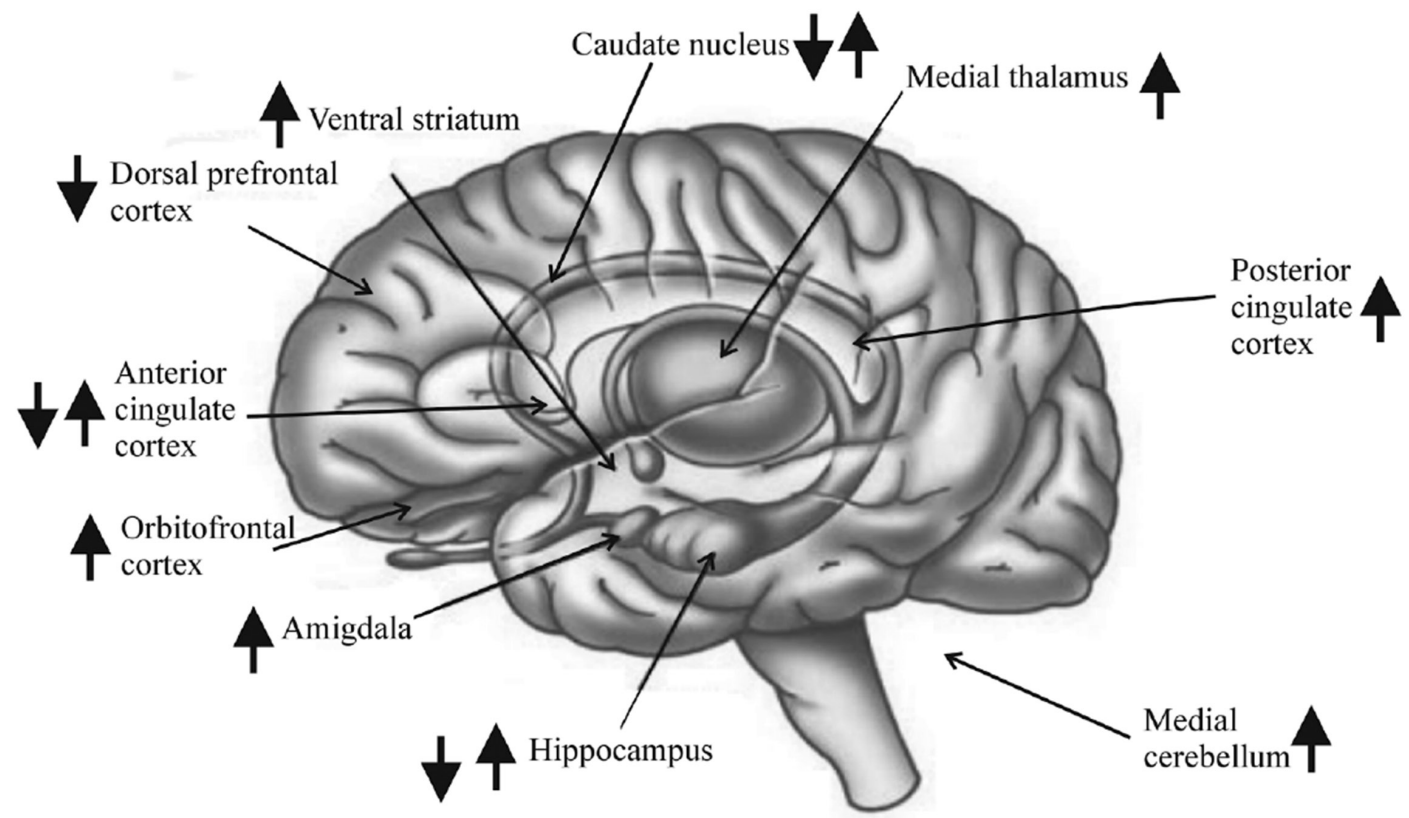

\section{$\downarrow 4 \begin{aligned} & \text { Pathological areas related to depression } \\ & \text { Indicates direction of metabolic abnormality relative to control }\end{aligned}$}

Figure 1. Anatomic areas related to neuropsychiatric findings in neurologic disorders. Arrows indicate increase and decrease of metabolic activity in the related regions in depression 
other psychiatric rating scales such as the Montgomery Åsberg Depression Rating scale, Zung Depression scale, beck depression inventory (BDI), Hamilton Rating scale (5) or a self-rating mood scale could be used for the assessment of depression. A neurologist should perform a detailed medical examination, blood, and hormonal tests, and a mental status examination to determine if speech, reasoning, behavior or memory have been affected, and to discriminate other causes of symptoms. Testosterone levels should be evaluated to diagnose or rule out hypogonadism, a cause of depression in men (6). The common feature of all of these is the presence of empty, sad or irritable mood, with cognitive and somatic abnormalities that significantly affect the individual's capacity of daily life activity. The main distinction between them is issues of timing, duration or assumed etiologic factors.

\section{Depression in Vascular Diseases}

In a series of distinguished studies, Robinson and Starkstein (7) and other investigators $(8,9)$ demonstrated that depression was a frequent complication of stroke. Some form of depression was noticed in one-quarter of patients in the first year after stroke $(10,11,12)$, with the period of higher risk being the first few months after onset $(13,14)$. Previous individual studies showed that depressive symptoms were found in one-third of all patients with stroke during follow-up. In the hospital-based study, the frequency of depression was $36 \%$ in the acute term, $32 \%$ in the medium term, and $34 \%$ in the long-term (14). Community studies have generally reported somewhat lower prevalence rates than studies conducted in hospitals. For instance, The Oxfordshire Community Stroke Project (15), a population-based study showed that, in stroke survivors, the frequency of depression was $20 \%$ in the BDI, and $11 \%$ in present state examinations. It is well-recognized that personal or family history of depression increases the risk for depression (16). It was reported that the use of antidepressants at entry or during follow-up varied from $0 \%$ in the first few weeks (17) to $31 \%$ at two years after stroke (18). Adequately treated patients (i.e. those using antidepressants who did not fulfill the criteria for depression) at the time of examination in any one study was $84 \%$ (19). Inadequately treated patients receiving antidepressants (i.e. those on antidepressants who still fulfilled criteria for depression) was $71 \%$ (20), but this frequency varied between $17 \%$ and $36 \%$ in most studies $(21,22)$.

Today, the large amount of cumulated data suggest that early depression treatment may be generally effective in improving mood, functional recovery, and quality of life (QoL) after stroke, but guidelines for the best treatment and its duration need to be established with input from stroke neurologists.

\section{Depression in Dementia}

In an elderly person showing a significant decrease in cognition and function, differential diagnosis should include dementia and a depressive disorder. These are not mutually exclusive. In aged people, depression and dementia are both common disorders. The lifetime prevalence of major depressive disorder has been presumed at $14.4 \%$. In nursing homes, the prevalence of depression was $54 \%$ (23). Among individuals aged 71 or older, the prevalence of dementia was $13.9 \%$, which is equivalent to 3.4 million individuals in the United States of America (USA) (24). It is well known that depressive symptoms are quite common in older people. Moreover, long-term major depressive episodes are more common in those with dementia than in age-matched controls without dementia. The incidence of depression in Alzheimer's disease (AD) and vascular dementia can be as high as $30 \%$, and over $40 \%$ in dementia associated with Huntingdon's disease and Parkinson's disease (PD) $(25,26)$.

The symptoms of major depression in dementia are usually not different from the depression that occurs in different diseases causing depression (27). Mood is most often low, but it may be anxious, irritable, or angry. Uncomfortable biologic rhythms are common in sleep, appetite, and energy, and patients can be negative, hopeless and even nihilistic. Ideas of worthlessness, guilt, and self-harm also occur. General cognitive ability can be significantly reduced due to depression. Some signs of dementia may strongly resemble those of major depression such as social withdrawal, lack of interest in self or others, low initiative, and poor motivation. The diagnosis of depression may be made more difficult when the dementia has not been previously recognised. Typically, a major depressive episode develops over weeks to a few months, and is a significant new impairment for the person. On the contrary, dementia may develop insidiously for months or years alone, and may be slow in progression. In an older adult, the onset of the first major depression may be the first sign of dementia, developing or at risk for development $(28,29)$. The diagnosis of dementia will be difficult until the depressive episode has remitted or at least improved. For someone with a known dementia, of any severity, who exhibits some of the symptoms and signs of major depression, the physician should consider and investigate the possibility of a new or deteriorating physical illness and the possibility of delirium, an acute deterioration in the dementia, a major depressive episode or the impact of prescribed and nonprescribed medicines and substances (30).

Depression and cognitive disorders, including dementia and mild cognitive impairment (MCI), are common in the elderly. Depression is also a common feature of cognitive impairment although the symptoms of depression in cognitive impairment differ from depression without cognitive impairment. Premorbid depression approximately doubles the risk of subsequent dementia. Furthermore, cognitive impairment is a common finding of late-life depression, and continues frequently even after mood symptoms remission (31).

The concept of depression as risk factor for cognitive impairment has major public health implications. For example, Barnes and Yaffe (32) estimated that a $10 \%$ reduction in depression prevalence could result in 68.000 fewer AD cases in the USA and 326.000 fewer cases worldwide. Besides, it is not known whether depression treatment reduces the risk of cognitive impairment and preliminary studies results are limited. A Danish study of 37.658 patients with a depression diagnosis treated with antidepressants reported that continued use of older antidepressants (primarily tricyclic antidepressants), but not newer antidepressants [primarily selective serotonin reuptake inhibitors (SSRIs)], was associated with a decreased incidence of all-cause dementia and AD (33). Conversely, a study of 6998 cognitively healthy, postmenopausal woman showed that those taking antidepressants at baseline had a $70 \%$ increased risk of incident MCI at follow-up (34). A neurologist can differentiate depression and cognitive deficits and 
prefer a treatment with careful regard to the patient's comorbid conditions and the medication's adverse effect profile.

As summary, the relationship between depression and cognitive impairment is a result of the interaction of multiple variables. A sequential approach to the treatment of depression was recommended in patients with dementia: (i) a period of careful waiting for milder symptoms, (ii) psychosocial treatment program, (iii) a medication trial for more severe symptoms or if psychosocial interventions fail, and (iv) possible electroconvulsive therapy for refractory symptoms.

\section{Depression in Parkinson's Disease}

PD characterized by bradykinesia, tremor, and stiffness. However, clinical handling requires attention beyond motor characteristics and should include non-motor characteristics. This is due to the fact that many patients experience neuropsychiatric disorders, including depression, anxiety, psychosis, behavioral and cognitive changes, and sleep disorders throughout their course of PD (35). Neuropsychiatric symptoms are often more distressing than the motor aspects of PD (36). Depression may produce internal emotional distress, negative QoL, motor and cognitive deficits, functional impairment, and increased caregiver distress in patients with PD. The clinically significant depressive symptoms occur in $40-50 \%$ of patients (37). Therefore, depression is one of the most frequently reported neuropsychiatric disorders in PD.

In population studies of PD, less than half of those with depressive disturbances have major depression and others have milder "non-major" types of depression. In one meta-analysis of PD depression trials, the average prevalence of dysthymia, minor depression, and major depression was $22.5 \%, 36.6 \%$, and $24.8 \%$, respectively (38). In addition, subsyndromal depression, which is defined as clinically related depressive phenomena that do not meet the standardized diagnostic criteria for major or non-major depressive disorders, is also evident. For example, patients who experience depressive symptoms only during "off" states may be considered as having subsyndromal depression.

A few studies examining the incidence of PD depression indicate that depressive disorders may develop at any stage of PD (39). Frequently, affective disorders predate the onset of motor symptoms on average, 4-6 years before the diagnosis of PD (40). After PD diagnosis, the annual rates of newly diagnosed depressive disorders range from 1.86 to $10 \%$ (for major depression) (41) and, subsequently, may have a long-term or a recurrent course (42). Mood changes in the context of deep brain stimulation (DBS) for the treatment of motor dysfunction provide another perspective for investigating PD depression. Suicide, aggression, depression, and mania are among the affective and behavioral complications after DBS, particular subthalamic stimulation relative to pallidal or thalamic stimulation (43). Spread of the stimulation field to adjacent non-motor circuits, deviant electrode placement, or activation of inappropriate electrode contacts may result in stimulation-related mood changes. Subthalamic stimulation is hypothesized to inhibit serotonergic transmission via interconnections between the substantia nigra pars reticulata, medial prefrontal cortex, and ventral pallidum. On the other hand, DBS has become common in the treatment of depression such as obsessive compulsive disorder (OCD) and schizophrenia.
Depression rating scales and clinical interviews are used to examine depressive symptoms, as screening tools to predict the presence of major and minor depressive disorders, or to follow treatment response. An international survey with more than 1000 patients with PD found that more than $50 \%$ of respondents reported clinically significant depressive symptoms based on the BDI score (44). In many cases of PD patients, depressive symptom severity is mild to moderate. However, a significant number of patients with PD have moderate-to-severe depressive symptoms (45). Depressive symptoms are also more likely to accompany anxiety disorders, psychosis, and cognitive impairment (46).

Treatment of depressive disturbances is indicated when symptoms persist and contribute to distress or dysfunction. It is necessary to mention to patients, their families, and other colleagues that depressive disorders in PD are curable and amelioration is possible. The effect of untreated depression extends beyond mood symptoms; earlier initiation of dopaminergic therapy, more functional disability, faster physical and cognitive impairment, increased mortality, lower QoL, and increased caregiver burden (47). In clinical practice, when depressive disorders are underrecognized, and even when unidentified, they may go unnoticed and not treated (48).

Accumulating data suggest that depression treatment influence the outcome of motor symptoms. The strategy to treatment should be multidimensional, and individualized to the patient, including; education about the mood disturbance, facilitation of skills to improve strategies to cope with mood symptoms, medications as appropriate, and effective support. In clinical practice, it is well known that all traditional antidepressants studied in PD have been found to be safe and well tolerated; efficacy, relative to placebo, has been demonstrated for nortriptyline, venlafaxine extended release, desipramine, citalopram, and paroxetine, although the time course of the antidepressant response has differed (Table 2). Nortriptyline effectiveness has been observed after eight weeks (49), and both nortriptyline and paroxetine demonstrated longterm maintenance (i.e., six months) of treatment gains (50). The treatment is considered ineffective for a patient when a response is not observed within 12 weeks and the patient has received the maximum indicated doses. If the clinical response is insufficient, drug adjustments are indicated at any period. Dopamine agonists

\begin{tabular}{|c|c|}
\hline Class & Drugs \\
\hline SSRIs & $\begin{array}{l}\text { Citalopram, escitalopram, fluoxetine, fluvoxamine, } \\
\text { paroxetine, sertraline, vilazodone* }\end{array}$ \\
\hline SNRIs & Desvenlafaxine, duloxetine, venlafaxine \\
\hline MAOIs & $\begin{array}{l}\text { Isocaboxazid, phenelzine, selegiline, } \\
\text { tranylcypromine }\end{array}$ \\
\hline TCAs & $\begin{array}{l}\text { Amitriptyline, desipramine, doxepin, imipramine, } \\
\text { nortriptiline }\end{array}$ \\
\hline Others & Bupropion, mirtazapine \\
\hline
\end{tabular}


were sought as a primary treatment for PD depression with mixed results (51). Pramipexole showed small efficacy for decreasing depressive symptoms over 12 weeks (52). Antidepressant effect of pramipexole also noted in a randomized, open-label trials (53). Alternative treatment such as vagal nerve stimulation and left prefrontal repetitive transcranial magnetic stimulation (rTMS) are being explored in small randomized controlled trials, with encouraging results.

Depressive disorders in PD could be accompanied by higher rates of cognitive dysfunction, somatic symptoms, and psychiatric comorbidities (54), which are responsible for not responding to treatment and higher rates of disability, relapse, and recurrence, which should be treated by a neurologist along with a neuropsychiatrist in some circumstances.

\section{Depression in Multiple Sclerosis}

Charcot gave the first detailed clinicopathologic description of "disseminated sclerosis/sclérose en plaques" and psychiatric symptoms in his lectures at the Salpêtrière Hospital in the 19th century (55). Major depression is common in patients with multiple sclerosis (MS), with estimates of lifetime prevalence of major depression in MS as high as $50 \%$. A previous study reported a 12-month prevalence rate of $25.7 \%$ for major depression in people with MS in the 18-45 years age range (56). Another concern is that suicidal ideation is relatively common among people with MS and that depression in patients with MS is often not detected and treated. In addition, depression is an important determinant of QoL in MS and may well be the most important determining factor (57).

The high comorbidity rate between anxiety and mood disorders may indicate that anxiety disorders are common in patients with MS. Smith and Young (58) assessed the prevalence of both anxiety and depression in a sample of 88 consecutive patients attending an MS clinic, using the BDI and the Hospital Anxiety and Depression scale (HADS). They reported that $34 \%$ scored as "cases" for anxiety on the HADS with 22 patients (25\%) needing treatment for it (58).

Recent studies have shown that depression in MS is associated with lesions in specific areas of the central nervous system. Imaging studies to date vary widely in both their design and rigour and there are few if any unequivocal conclusions that can be made. However, on balance the evidence seems to favour an association between depression in MS with greater neuropathology in the left anterior temporal/parietal regions (59).

For patients with MS with depression, fatigue is not an uncommon symptom. Mohr et al. (60) noted that "there is a relationship between fatigue and depression in MS", but "when depression and fatigue are often considered to be related to MS, why or how this relationship might be" is not usually clearly defined (60). There is an unanswered question about whether fatigue is directly caused by brain lesions in MS or as a psychological reaction to a disease in a predisposed individual. However, there is a growing confirmation that fatigue in MS is multidimensional and both mental and physical fatigue should be evaluated (61). Treating depression in patients with MS does seem to produce improvements in self-reports of fatigue. However, the evidence to date is based upon one uncontrolled study of patients who received either cognitive behaviour therapy (CBT) or supportive group therapy or sertraline. SSRIs have been shown not to be useful in the treatment of chronic fatigue syndrome, whereas reversible inhibitors of monoamine oxidase inhibitor- $\mathrm{A}$ are useful in treating some aspects of fatigue syndromes, and CBT is helpful $(62,63)$. The primary concern for interferon therapy that causes depression in patients with MS seems unwarranted in the light of recent studies that address this issue (64). Early diagnosis and treatment of depression has so much clinical benefit, regarding this fact the neurologist should start antidepressant treatment immediately after diagnosis.

\section{Depression in Epilepsy}

Depresion is often under-recognized and improperly managed in patients with epilepsy, and can interfere with treatment outcomes and QoL and doubles the overall costs of medical care (65). Previous studies reported prevalence of lifetime depression in people with epilepsy ranging from $4.1 \%$ to $32.5 \%$ with an overall prevalence of $13.0 \%$.

Hippocrates stated that "melancholics are normally epileptic and epileptic, melancholic: They are the direction that the disease determines: If it happens in the body, epilepsy, if on intelligence, melancholia" (66). Epilepsy is now known as a disease of the brain presented not only by a tendency to produce epileptic seizures, but explicitly also by the cognitive, psychological, social, and neurobiologic consequences of this condition.

Some epidemiologic studies reported that depression may antedate and increase the risk of epilepsy onset (67). Paradoxically, depression can follow remission of epilepsy either after epilepsy surgery or the initiation of an effective antiepileptic drug, as part of the phenomenon of forced normalization first described by Landolt. Indeed, the first few months after epilepsy surgery, successful or otherwise, have been identified as being a period of increased risk for psychiatric disorders. Whichever one is developed, it is well known that low serotonin levels are historically defined in mood disorders as in epilepsy. The neurobiologic mechanisms shared with epilepsy and depression are the effect of stress through a hypothalamic-pituitary-adrenal (HPA)-mediated mechanism and disturbances of glutamate and $\gamma$-aminobutyric acid neurotransmitters (68). A hyperactive HPA axis has been found in both epilepsy and depression and may lead to substantive cortical changes, particularly in the volume of the hippocampus and frontal lobes. Social factors, such as a lack of occupational attainment, social engagement, or social support, may also influence the relationship between epilepsy and depression.

Anxiety disorders in epilepsy can also be classified based on the temporal correlation between symptoms and seizure occurrence (69). Preictal anxiety symptoms occur from several hours to several days before the seizure. The severity of the symptoms may increase as the time of the seizure approaches. Postictal fear occurs after a seizure and may persist for up to seven days thereafter; such persistence is more frequent among drug-resistant patients with partial epilepsy (70). Anxiety symptoms almost identical to the symptoms of psychiatric disorders may occur as semiologic manifestations during the seizure. Nervousness, fear, anger, and irritability may occur as auras of seizures. Fear occurs as an aura 
among $10-15 \%$ of patients with partial seizures, and ictal fear is of sudden onset and brief duration $(70,71)$. Seizures originating from the anteromedial area and cingulate gyrus may cause fear.

Although suicide represents $1 \%$ of all deaths in the general population, it accounts for $11.5 \%$ of all deaths in epilepsy. These figures are not so different from those of sudden unexpected death in epilepsy (SUDEP) that accounts for $18 \%$ of all deaths in epilepsy (72). However, as compared with SUDEP, suicide is still an unmentionable issue in epilepsy. The standard mortality ratio for suicide in patients with epilepsy is three times higher than the general population (73) and such a risk remains high even after excluding those with a history of psychiatric disorders and adjusting for socioeconomic factors (74).

Drug treatments, psychotherapy and rehabilitative care should be evaluated in isolation, in combination, and in comparison with each other. Antidepressant drug treatment in suicide prevention is also particularly warranted. Modern antidepressants, SSRIs, selective serotonine noradrenaline reuptake inhibitor (SNRIs), noradrenergic and specific serotonergic antidepressants are thought to be safe in epilepsy, but general practitioners and neurologists seem reluctant to adopt this approach. In contrast, tricyclic or tetracyclic antidepressants and norepinephrine-dopamine reuptake inhibitors should be avoided in the first instance. Neurologists will benefit from knowing how to initiate pharmacotherapy for major, dysthymic, and minor depressive episodes, but should refer the patient to a psychiatrist for the following; depressive episode associated with suicidal ideation, major depression with psychotic features, bipolar disorder, and any major depressive or dysthymic episode that has failed to respond to a prior trial of SSRI and SNRI at optimal doses.

\section{Depression and Brain Trauma}

Depression is common after traumatic brain injury (TBI). In the first year after brain injury, rates range from 14 to $42 \%$ (compared with a population rate of $2.1 \%$ ). One study showed that the rate of depression was $31 \%$ in one month and $17 \%$ in three to five years after injury. The rates of other disorders in patients with TBI are generalized anxiety disorder 3-28\%, panic disorder $4-17 \%$, phobic disorders $1-10 \%$, and posttraumatic stress disorder 3-27\% (75,76). Depression does not arise from a single known pathogenic mechanism. There are multiple factors that affect and determine the neuropsychiatric sequelae of TBI including the severity and type of injury, past psychiatric diagnosis, sociopathy, pre-morbid behavioral problem, social support, substance abuse, preexisting neurologic disorder, age, and apolipoprotein E status. Accumulating evidence indicates that inflammatory pathways may contribute to the development of depression, at least in a subset of patients. Given that inflammation can persist for years after a TBI, it is logical to speculate that the chronic low-grade inflammation seen after a TBI could be mechanistically linked to the high rates of depression following a TBI (77). The symptoms of the injury are correlated with the type of damage sustained. Patients who suffer from direct axonal injury usually experience a problem with arousal, slow cognitive processing, and attention (78). Age is a significant factor in the development of psychiatric symptoms, for example, older people with TBI have a longer agitation period, greater cognitive impairment, and a higher possibility to develop mass lesions and permanent disability as compared to younger victims.

Sadness is the most prevalent reaction after TBI as patients regret the loss of their past lives. The Hamilton Rating scale for depression or the BDI have been reported to evaluate depression after TBI, but it is more important to evaluate the patients clinically. High scores on the BDI represent hyperreactivity to post-TBI symptoms instead of depression. Patients with TBI may not encounter typical signs of depression such as somatic symptoms that are essential to diagnose depression (79). Mood liability is a frequent manifestation of depression after brain injury. Other symptoms that manifest in brain injury such as apathy, decreased motivation, schizoid behavior, impaired thought process, and cognitive dysfunction can resemble depression (80).

An intensive team approach is needed to collaborate with the expertise of neurologists, psychiatrists, and psychologists for the efficient management of the patients. A careful assessment is required to get an accurate description of patient's functional and neurobehavioral status after the injury. Patients experiencing suicidal thoughts need aggressive psychological rehabilitation and care.

\section{Depression and Neurosurgery}

Neurosurgery for the treatment of depression has been used to isolate relatively large areas of the limbic system from the rest of the brain. Selective leukotomy was later performed based on the increased knowledge of the role played by brain limbic circuits in the processing of emotions. A selective lesion approach was developed with the introduction of stereotactic techniques. However, neurosurgery was seen only as a suitable treatment of severe depression as Benabid introduced the technique of frequencydependent chronic electrical stimulation (81). Moreover, rTMS and transcranial direct current stimulation are promising non-invasive brain stimulation methods used to treat various neuropsychiatric disorders, including PD, schizophrenia, OCD, chronic pain, and major depression (Figure 2) (82,83). Due to its non-destructive nature, these procedures will undoubtedly be preferred in the future. Frequency-dependent chronic electrical stimulation should be accompanied by newer techniques such as microdialysis and reverse dialysis, simultaneous functional magnetic resonance imaging, and/or positron emission tomography scanning, and the use of chemicals for microinfusion or in situ placement of the reactivated-stem cells (84). To reach success, these modern methods will require a new classification of depression based on current neurobiologic criteria.

\section{Conclusion}

Depression is not uncommon in neurologic practice. It may be overlooked and untreated. Recent diagnostic criteria and scoring methods have enabled us to identify depression more quickly and clearly. The approach to treatment should be individualized to the patient, including appropriate drugs and strategies for cooperation with the neurologist, clinical neuropsychologists, psychiatrists, and geriatricians. 

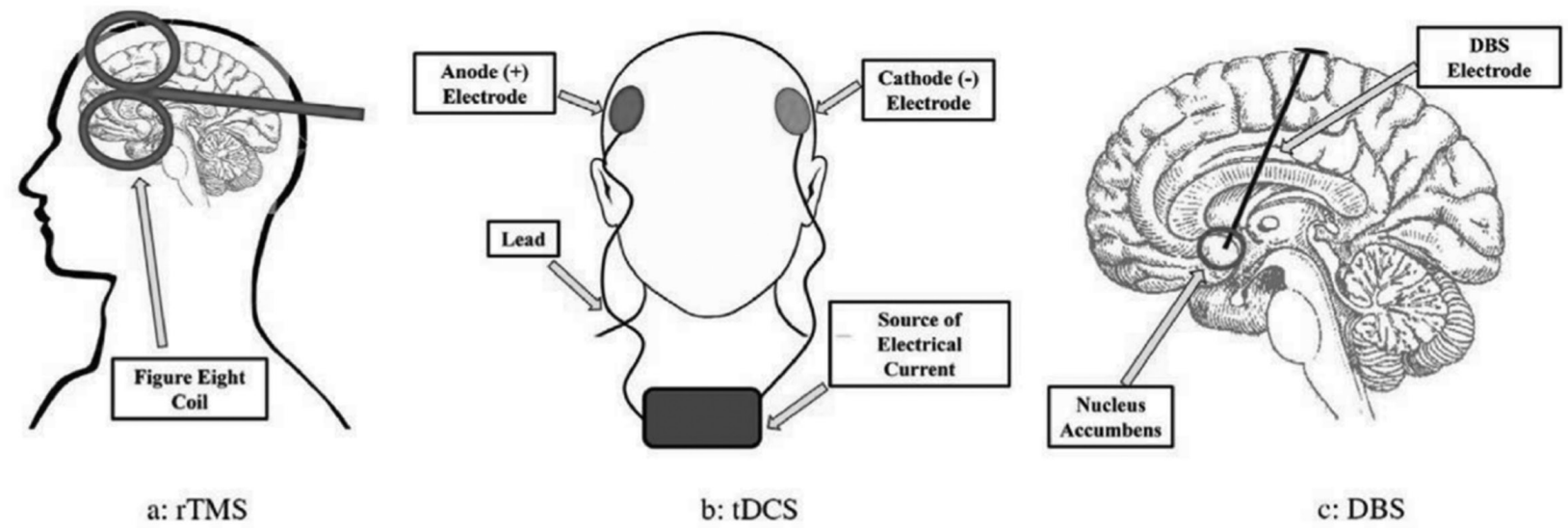

Figure 2. Schematic illustration of three brain stimulation techniques: (a) Repetitive Transcranial Magnetic Stimulation, (b) Transcranial Direct Current Stimulation, and (c) Deep Brain Stimulation

rTMS: Repetitive Transcranial Magnetic Stimulation, tDCS: Transcranial Direct Current Stimulation, DBS: Deep Brain Stimulation

\section{Ethics}

Peer-review: Externally peer-reviewed.

\section{Authorship Contributions}

Surgical and Medical Practices: E.K., Concept: E.K., F.E.B., Design: E.K., Data Collection or Processing: E.K., Analysis or Interpretation: F.E.B., Literature Search: F.E.B., Writing: F.E.B.

Conflict of Interest: No conflict of interest was declared by the authors.

Financial Disclosure: The authors declared that this study received no financial support.

\section{References}

1. Veazey C, Aki SOE, Cook KF, Lai EC, Kunik ME. Prevalence and treatment of depression in Parkinson's disease. J Neuropsychiatry Clin Neurosci 2005; 17:310-323.

2. Leentjens AF, Verhey FR, Luijckx GJ, Troost J. The validity of the Beck Depression Inventory as a screening and diagnostic instrument for depression in patients with Parkinson's disease. Mov Disord 2000;15:1221-1224.

3. Weintraub D, Newberg AB, Cary MS, et al. Striatal dopamine transporter imaging correlates with anxiety and depression symptoms in Parkinson's disease. J Nucl Med 2004;46:227-232.

4. American Psychiatric Association. Diagnostic and Statistical Manual of Mental Disorders (5th ed). Arlington, VA: American Psychiatric Publishing, 2013.

5. Moran PJ, Mohr DC. The validity of Beck Depression Inventory and Hamilton Rating Scale for Depression items in the assessment of depression among patients with multiple sclerosis. J Behav Med 2005;28:35-41.

6. Shores MM, Sloan KL, Matsumoto AM, Moceri VM, Felker B, Kivlahan DR. Increased incidence of diagnosed depressive illness in hypogonadal older men. Arch Gen Psychiatry 2004;61:162-167.

7. Starkstein SE, Cohen BS, Fedoroff P, Parikh RM, Price TR, Robinson RG. Relationship between anxiety disorders and depressive disorders in patients with cerebrovascular injury. Arch Gen Psychiatry 1990;47:246-251.

8. Jorgensen L, Engstad T, Jacobsen BK. Higher incidence of falls in long-term stroke survivors than in population controls: depressive symptoms predict falls after stroke. Stroke 2002;33:542-547.

9. Pohjasvaara T, Vataja R, Leppavuori A, Kaste M, Erkinjuntti T. Depression is an independent predictor of poor long-term functional outcome post-stroke. Eur J Neurol 2001;8:315-319.
10. Laska AC, Martensson B, Kahan T, von Arbin M, Murray V. Recognition of depression in aphasic stroke Patients. Cerebrovasc Dis 2007;24:74-79.

11. Vataja R, Leppavuori A, Pohjasvaara T, et al. Poststroke depression and lesion location revisited. J Neuropsychiatry Clin Neurosci 2004;16:156162.

12. Verdelho A, Henon H, Lebert F, Pasquier F, Leys D. Depressive symptoms after stroke and relationship with dementia: A three-year follow-up study. Neurology 2004;62:905-911.

13. Hackett ML, Anderson CS, House AO. Management of depression after stroke: a systematic review of pharmacological therapies. Stroke 2005;36:10981103.

14. Andersen G, Vestergaard K, Riis J, Lauritzen L. Incidence of poststroke depression during the first year in a large unselected stroke population determined using a valid standardized rating scale. Acta Psychiatr Scand 1994;90:190-195.

15. House A, Dennis M, Mogridge L, Warlow C, Hawton K, Jones L. Mood disorders in the year after first stroke. Br J Psychiatry 1991;158:83-92.

16. Charney DS, Reynolds CF, Lewis L, et al. Depression and Bipolar Support Alliance. Depression and Bipolar Support Alliance consensus statement on the unmet needs in diagnosis and treatment of mood disorders in late life. Arch Gen Psychiatry 2003;60:664-672.

17. Spalletta G, Guida G, De Angelis D, Caltagirone C. Predictors of cognitive level and depression severity are different in patients with left and right hemispheric stroke within the first year of illness. J Neurol 2002;249:15411551.

18. King RB, Shade-Zeldow Y, Carlson CE, Feldman JL, Philip M. Adaptation to stroke: a longitudinal study of depressive symptoms, physical health, and coping process. Top Stroke Rehabil 2002;9:46-66.

19. Desmond DW, Remien RH, Moroney JT, Stern Y, Sano M, Williams JB. Ischemic stroke and depression. J Int Neuropsychol Soc 2003;9:429-439.

20. Ng KC, Chan KL, Straughan PT. A study of post-stroke depression in a rehabilitative center. Acta Psychiatr Scand 1995;92:75-79.

21. Löfgren B, Gustafson Y, Nyberg L. Psychological well-being 3 years after severe stroke. Stroke 1999;30:567-572.

22. Verdelho A, Henon H, Lebert F, Pasquier F, Leys D. Depressive symptoms after stroke and relationship with dementia: a three-year follow-up study. Neurology 2004;62:905-911.

23. Engedal K, Barca ML, Laks J, Selbaek G. Depression in Alzheimer's disease: specificity of depressive symptoms using three different clinical criteria. Int J Geriatr Psychiatry 2011;26:944-951.

24. Enache D, Winblad B, Aarsland D. Depression in dementia: epidemiology, mechanisms, and treatment. Curr Opin Psychiatry 2011;24:461-472. 
25. Reijnders JS, Ehrt U, Weber WE, Aarsland D, Leentjens AF. A systematic review of prevalence studies of depression in Parkinson's disease. Mov Disord 2008;23:183-189.

26. Royall DR, Palmer R, Chiodo LK, Polk MJ. Depressive symptoms predict longitudinal change in executive control but not memory. Int J Geriatr Psychiatry 2012;27:89-96.

27. Pellegrino LD, Peters ME, Lyketsos CG, Marano CM. Depression in cognitive impairment. Curr Psychiatry Rep 2013;15:384.

28. Sobin C, Sacheim HA. Psychomotor symptoms of depression. Am J Psychiatry 1997;154:4-17.

29. Reichman WE, Coyne AC. Depressive symptoms in Alzheimer's disease and multi-infarct dementia. J Geriatr Psychiatry Neurol 1995;8:96-99.

30. Boyle LL, Porsteinsson AP, Cui X, King DA, Lyness JM. Depression predicts cognitive disorders in older primary care patients. J Clin Psychiatry 2010;71:74-79.

31. Unützer J. Clinical practice. Late-life depression. $N$ Engl J Med 2007;357:2269-2276.

32. Barnes DE, Yaffe $K$. The projected effect of risk factor reduction on Alzheimer's disease prevalence. Lancet Neurol 2011;10:819-828.

33. Banerjee S, Hellier J, Dewey M, et al. Sertraline or mirtazapine for depression in dementia (HTA-SADD): a randomised, multicentre, double-blind, placebo-controlled trial. Lancet 2011;378:403-411.

34. Goveas SJ, Hogan PE, Kotchen JM, et al. Depressive symptoms, antidepressant use, and future cognitive health in postmenopausal women: the Women's Health Initiative Memory Study. Int psychogeriatr 2012;24:1252-1264.

35. Aarsland D, Marsh L, Schrag A. Neuropsychiatric symptoms in Parkinson's disease. Mov Disord 2009;24:2175-2186.

36. Hely MA, Morris JG, Reid WG, Trafficante R. Sydney multicenter study of Parkinson's disease: non-L-dopa-responsive problems dominate at 15 years. Mov Disord 2005;20:190-199.

37. Reijnders JS, Ehrt U, Weber WE, Aarsland D, Leentjens AF. A systematic review of prevalence studies of depression in Parkinson's disease. Mov Disord 2008;23:183-189.

38. Slaughter JR, Slaughter KA, Nichols D, Holmes SE, Martens MP. Prevalence, clinical manifestations, etiology, and treatment of depression in Parkinson's disease. J Neuropsychiatry Clin Neurosci 2001;13:187-196.

39. Global Parkinson's Disease Survey (GPDS) Steering Committee. Factors impacting on quality of life in Parkinson's disease: results from an international survey. Mov Disord 2002;17:60-67.

40. Ishihara L, Brayne C. A systematic review of depression and mental illness preceding Parkinson's disease. Acta Neurol Scand 2006;113:211-220.

41. Aarsland D, Pahlhagen S, Ballard CG, Ehrt U, Svenningsson P. Depression in Parkinson disease - epidemiology, mechanisms, and management. Nat Rev Neurol 2012;8:35-47.

42. Brown RG, MacCarthy B, Gotham AM, Der GJ, Marsden CD. Depression and disability in Parkinson's disease: a follow-up of 132 cases. Psychol Med 1988;18:49-55.

43. Rodriguez-Oroz MC, Obeso JA, Lang AE, et al. Bilateral deep brain stimulation in Parkinson's disease: a multi-centre study with 4 years followup. Brain 2005;128:2240-2249.

44. Global Parkinson's Disease Survey (GPDS) Steering Committee. Factors impacting on quality of life in Parkinson's disease: results from an international survey. Mov Disord 2002;17:60-67.

45. van der Hoek TC, Bus BA, Matui P, van der Marck MA, Esselink RA, Tendolkar I. Prevalence of depression in Parkinson's disease: effects of disease stage, motor subtype and gender. J Neurol Sci 2011;310:220-224.

46. Rojo A, Aguilar M, Garolera MT, Cubo E, Navas I, Quintana S. Depression in Parkinson's disease: clinical correlates and outcome. Parkinsonism Relat Disord 2003;10:23-28.

47. Menza M, Dobkin RD, Marin H, et al. The impact of treatment of depression on quality of life, disability and relapse in patients with Parkinson's disease. Mov Disord 2009;24:1325-1332.

48. Ravina B, Elm J, Camicioli R, et al. The course of depressive symptoms in early Parkinson's disease. Mov Disord 2009;24:1306-1311.

49. Price A, Rayner L, Okon-Rocha E, et al. Antidepressants for the treatment of depression in neurological disorders: a systematic review and meta-analysis of randomised controlled trials. J Neurol Neurosurg Psychiatry 2011;82:914923.

50. van der Marck MA, Bloem BR, Borm GF, Overeem S, Munneke M, Guttman M. Effectiveness of multidisciplinary care for Parkinson's disease: a randomized, controlled trial. Mov Disord 2013;28:605-611.

51. Barone P, Poewe W, Albrecht S, et al. Pramipexole for the treatment of depressive symptoms in patients with Parkinson's disease: a randomised, double-blind, placebo-controlled trial. Lancet Neurol 2010;9:573-580.

52. Andersen J, Aabro E, Gulmann N, Hjelmsted A, Pedersen HE. Antidepressive treatment in Parkinson's disease A controlled trial of the effect of nortriptyline in patients with Parkinson's disease treated with L-DOPA. Acta Neurol Scand 1980;62:210-219.

53. Menza M, Dobkin RD, Marin H, et al. A controlled trial of antidepressants in patients with Parkinson disease and depression. Neurology 2009;72:886892.

54. Seppi K, Weintraub D, Coelho M, et al. The Movement Disorder Society evidence-based medicine review update: treatments for the non-motor symptoms of Parkinson's disease. Mov Disord 2011;26(Suppl 3):42-80.

55. Butler MA, Bennett TL. In search of a conceptualization of multiple sclerosis: a historical perspective. Neuropsychol Rev 2003;13:93-112.

56. Feinstein A. The neuropsychiatry of multiple sclerosis. Can J Psychiatry 2004;49:157-163.

57. Janardhan V, Bakshi R. Quality of life in patients with multiple sclerosis: the impact of fatigue and depression. J Neurol Sci 2002;205:51-58.

58. Smith SJ, Young CA. The role of affect on the perception of disability in multiple sclerosis. Clin Rehabil 2000;14:50-54.

59. Harrison PJ. The neuropathology of primary mood disorder. Brain 2002;125:1428-1449.

60. Mohr DC, Boudewyn AC, Goodkin DE, Bostrom A, Epstein L. Comparative outcomes for individual cognitive-behavior therapy, supportive-expressive group psychotherapy, and sertraline for the treatment of depression in multiple sclerosis. J Consult Clin Psychol 2001;69:942-949.

61. Schiffer RB, Wineman NM. Antidepressant pharmacotherapy of depression associated with multiple sclerosis. Am J Psychiatry 1990;147:1493-1497.

62. Patten SB, Metz LM; SPECTRIMS Study Group. Interferon betala and depression in secondary progressive MS: Data from the SPECTRIMS Trial. Neurology 2002;69:744-746.

63. Hickie IB, Wilson AJ, Wright JM, Bennett BK, Wakefield D, Lloyd AR. A randomized, double-blind placebo-controlled trial of moclobemide in patients with chronic fatigue syndrome. J Clin Psychiatry 2000;61:643-648.

64. Patten SB, Metz LM. Interferon beta-1 a and depression in relapsingremitting multiple sclerosis: an analysis of depression data from the PRISMS clinical trial. Mult Scler 2001;7:243-248.

65. Lin JJ, Mula M, Hermann BP. Uncovering the neurobehavioural comorbidities of epilepsy over the lifespan. Lancet 2012;380:1180-1192.

66. Temkin O. The falling sickness. Baltimore: The Johns Hopkins University Press, 1994.

67. Hesdorffer DC, Ishihara L, Mynepalli L, Webb DJ, Weil J, Hauser WA. Epilepsy, suicidality, and psychiatric disorders: a bidirectional association. Ann Neurol 2012;72:184-191.

68. Kanner AM. Can neurobiological pathogenic mechanisms of depression facilitate the development of seizure disorders? Lancet Neurol 2012;11:10931102.

69. Hesdorffer DC, Ishihara L, Mynepalli L, Webb DJ, Weil J, Hauser WA. Epilepsy, suicidality, and psychiatric disorders: a bidirectional association. Ann Neurol 2012;72:184-191.

70. Kanner AM, Ettinger AB. Anxiety disorders. In: Engel J Jr, Pedley TA, editors. Epilepsy: a Comprehensive Textbook. 2nd ed. Philadelphia: Wolters Kluwer/Lippincott Williams \& Wilkins, 2008:2139-2154.

71. 71 Devinsky O, Vazquez B. Behavioral changes associated with epilepsy. Neurol Clin 1993;11:127-149.

72. Tellez-Zenteno JF, Patten SB, Jetté N, Williams J, Wiebe S. Psychiatric comorbidity in epilepsy: a population-based analysis. Epilepsia 2007; $48: 2336-2344$.

73. Bell GS, Gaitatzis A, Bell CL, Johnson AL, Sander JW. Suicide in people with epilepsy: how great is the risk? Epilepsia 2009;50:1933-1942. 
74. Christensen J, Vestergaard M, Mortensen PB, Sidenius P, Agerbo E. Epilepsy and risk of suicide: a population-based case-control study. Lancet Neuro 2007;6:693-698.

75. Dikmen S, Bombadier CH, Machamer JE, Fann JR, Temkin NR. Natural history of depression in traumatic brain injury. Arch Phys Med Rehabil 2004;85:1457-1464.

76. Moldover JE, Goldberg KB, Prout MF. Depression after traumatic brain injury: a review of evidence for clinical heterogeneity. Neuropsychol Rev 2004; $14: 143-154$

77. Jorge RE, Robinson RG, Moser D, Tateno A, Crespo-Facorro B, Arndt S Major depression following traumatic brain injury. Arch Gen Psychiatry 2004;61:42-50.

78. Levin HS, McCauley SR, Josic CP, et al. Predicting depression following mild traumatic brain injury. Arch Gen Psychiatry 2005;62:523-528.

79. Rowland SM, Lam CS, Leahy B. Use of the Beck Depression InventoryII (BDI-II) with persons with traumatic brain injury. Analysis of factorial structure. Brain Inj 2005;19:77-83.
80. Marin RS, Wilkosz PA. Disorders of diminished motivation. J Head Trauma Rehabil 2005;20:377-388

81. Benabid AL, Benazzouz A, Hoffmann D, Limousin P, Krack P, Pollak P. Long term electrical inhibition of deep brain targets in movement disorders. Mov Disord 1998;13(Suppl 3):119-125.

82. Fitzgerald PB, Segrave RA. Deep brain stimulation in mental health: Review of evidence for clinical efficacy. Aust N Z J Psychiatry 2015;49:979-993.

83. Perera T, George MS, Grammer G, Janicak PG, Pascual-Leone A, Wirecki TS. The Clinical TMS Society Consensus Review and Treatment Recommendations for TMS Therapy for Major Depressive Disorder. Brain Stimul 2016;9:336-346.

84. Bejjani BP, Damier P, Arnulf I, et al. Transient acute depression by highfrequency deep-brain stimulation. N Engl J Med 1999;340:1476-1480. 